\title{
Elementos pedagógicos significativos del discurso de Jesucristo
}

\section{Significant pedagogical elements of the discourse of Jesus Christ}

\author{
Edgar Larco Camacho \\ Universidad Internacional del Ecuador, Ecuador
}

Autor para correspondencia: edgarlarco@gmail.com

Fecha de recepción: 10 de junio de 2016 - Fecha de aceptación: 25 de julio de 2016

\begin{abstract}
Resumen
El objetivo de este estudio es encontrar la significatividad de los elementos pedagógicos del discurso de Jesucristo: ser, saber, hacer y sostener, para conocer su pertinencia en la actualidad. El levantamiento de la información se hizo mediante encuestas. Se contó con 16 indicadores de cuatro variables predictoras para medir la variable dependiente "Elementos Pedagógicos del Discurso de Jesucristo", además de las variables sociodemográficas intervinientes. Los resultados permitieron encontrar que, al medir el grado de relación, entre las variables predictoras y la variable dependiente, se encontró que existe correlación bivariada positiva significativa (ser $=, 732$; saber $=, 702$; hacer $=, 848$ y sostener $=, 692$ ) en donde el elemento pedagógico hacer, registró mayor significatividad, seguido del factor ser. Esto en base al coeficiente de correlación de Pearson. Finalmente, se puede concluir que, si son significativos los elementos pedagógicos del discurso de Jesucristo, para los nuevos estudiantes de la UIDE. Como parte de la metodología utilizada, se desarrolló un estudio transversal. El estadístico o coeficiente de fiabilidad fue de 0,857 expresado por el valor del alfa de Cronbach.
\end{abstract}

Palabras claves: elementos pedagógicos del discurso de Jesucristo; ser; saber; hacer; sostener

Abstract: The objective of this study is to find the significance of teaching elements of discourse of Jesus Christ: being, knowing, doing and to hold, to know its relevance today. The gathering of information was done through surveys. It featured 16 indicators four predictor variables to measure the dependent variable "Pedagogic Discourse Elements of Jesus Christ", in addition to sociodemographic variables involved. The results allowed to find that by measuring the degree of relationship between the predictor variables and the dependent variable, it was found that there bivariate correlation positive significant (be $=, 732$; namely $=, 702$; do $=, 848$ and hold $=, 692$ ) where the pedagogical element to do, recorded greater significance, followed by being factor. This based on the Pearson correlation coefficient. Finally, we can conclude that if are significant elements of discourse teaching of Jesus Christ, for new students UIDE. As part of the methodology used, a cross-sectional study was conducted. Statistical or reliability coefficient was 0.857 expressed by the value of Cronbach.

Key words: pedagogical elements of the speech of Jesus Christ; to be; to know; to do; to hold 


\section{Introducción}

\section{Elementos Pedagógicos del discurso de Jesucristo}

El 21 de diciembre de 1968 mientras los ojos del mundo miraban con asombro el orbitar alrededor de la luna, el mundo escuchó con sorpresa la lectura de los primeros versículos del primer capítulo del libro del Génesis. Durante el retorno a la tierra, el hijo de un controlador del centro de mando quiso conocer de su padre quién piloteaba la nave. La pregunta fue derivada a los tripulantes que venían de regreso a casa, el piloto del módulo lunar William Anders respondió: "Creo que Sir Isaac Newton es quien hace la mayor parte del trabajo en este momento" (Hamel \& Breen, 2008)

La misma pregunta podría ser replanteada. ¿Quién dirige los modelos pedagógicos de aprendizaje de la comunidad? Alguien dirá, "El ministerio de Educación" o "el director ejecutivo" o "el docente". Cada respuesta es correcta, pero existe la posibilidad de que no sea toda la verdad. Es posible que sean algunos teóricos fallecidos hace tiempo, quienes inventaron las teorías que se replican en la actualidad, quienes aportan con los supuestos epistemológicos que fundamentan la práctica docente.

En la actualidad, la enseñanza se encuentra en una encrucijada delicada. Las crisis económicas que zarandean las decisiones políticas, que minan los recursos afectando una educación de calidad. Los recursos digitales que revolucionan la estabilidad clásica de la docencia, están obligando a incorporar innovaciones pedagógicas para superar la mera transmisión de conocimientos, como el mejoramiento de las interacciones sociales y profesionales. La necesidad del apuntalamiento de los aspectos emocionales y actitudinales, el mejoramiento de disposiciones subjetivas de análisis y reflexión personal, las creencias y hábitos conscientes e inconscientes que condicionan los modos del ser, del saber, del sostener y del hacer son razones suficientes para revisar la historia humana y encontrar los insumos que favorezcan una labor educativa holística con miras a la restauración primigenia del ser humano.

En esta labor, como la de los tripulantes de la primera nave en orbitar la tierra, es preciso recordar los orígenes. Desde los inicios de la literatura veterotestamentaria como la neotestamentaria, se señala a Jesucristo encarnando la labor de un maestro. Así, por ejemplo, en los evangelios el verbo enseñar figura más de cien veces, siempre en referencia al Mesías. El término maestro es aplicado a Jesús, por parte de sus discípulos (Marcos 4.38); por los discípulos de Juan (Juan 1.38), por Pedro (Marcos 9.5), por Judas (Mateo 26.25, por sus detractores (Mateo 22.15-17; 22.23, 24) como por quienes querían seguirlo (Mateo 19.16; Marcos 10.17). Lo significativo del discurso es que Jesús mismo se llamó “maestro" (Lucas 22.11; Marcos 14.14: Juan 13.12-15).

En los evangelios, el termino rabí o maestro, asignado a Jesucristo, le reconocía connotaciones particulares. Era un título honorífico (Juan 1.38; 20.16); de uso exclusivo (Mateo $23.7,8$ ), todos sus discípulos lo reconocen con este título (Juan 4.31), de igual manera por parte María Magdalena (Juan 20.16). 
La posición social del maestro en los tiempos de Cristo se relacionaba con una clase superior. Este atributo era reconocido por el saber del sujeto. Un maestro debía tener una preparación para legislar en asuntos religiosos y legales. Con capacidad para ligar y desligar (Mateo 16.19) y debía ser tratado con el distintivo de "Rabí". Sin embargo, en el caso de Jesucristo es atípico; no había cumplido con los estudios necesarios (Juan 7.12-15; Marcos 6.14), no tenía título de "doctor ordenado", no pertenecía al grupo sacerdotal, no era fariseo, muchos se preguntaban de su sabiduría y de la forma como enseñaba (Lucas 4.22; Mateo 13.53$58)$.

Su labor de enseñanza fue sencilla. Usó un lenguaje vigoroso y simple, lo que asombraba a sus oyentes (Mar 1.21, 22). Las personas de diversos estratos sociales; culturales, económicos, etc., podían comprenderlo. No dejaba perplejos a los ignorantes, ni empleaba palabras pocos comunes e intelectuales que no pudieran entenderlo. Es posible señalar que el mayor maestro que el mundo ha conocido, fue definido, simple y práctico en sus discursos y enseñanzas compartidas con sus oyentes. Los recursos que usó, todavía tienen significancia, a pesar de los esfuerzos conscientes o no, por relegar su legado.

La visión de una educación vista como alternativa redentora, es posible. Las políticas que fomentan la competencia individualista, que aniquilan las posibilidades de desarrollo del otro, poco favorecen a la humanidad. El espíritu de competitividad; la violencia en los centros educativos, los problemas de aprendizaje, etc., son temas que han propiciado el estudio de esta situación problemática, influenciada entre otros factores, por los modelos pedagógicos tradicionales (Bernal \& María, 2013), tanto a nivel de país como foráneos. Sumados a los esfuerzos del mejoramiento de condiciones estructurales, se hacen necesarios optimizar esfuerzos que consoliden un clima de convivencia propicio que favorezca el aprendizaje, tendiente a construir un mejor desempeño escolar y de calidad (Secretaría Nacional de Planificación y Desarrollo - Senplades, 2013). Finalmente, la premisa a desarrollar, está orientada a afirmar los factores pedagógicos del discurso de Jesucristo son significativos. Siendo éste, el objetivo general de esta investigación.

\section{Explore la importancia del problema}

La importancia de esta situación problemática educativa actual es de preocupación general. Según un informe de la UNESCO, los países de América Latina y el Caribe han centrado sus modelos pedagógicos en visiones instrumentalistas y/o reduccionistas, que es preciso superar en la educación del siglo XXI (Blanco, 2007). Un cambio paradigmático epistemológico en la manera de estructurar y evaluar el sistema educativo, es un imperativo. La incorporación de convencionalismos humanistas ha devenido en olas temporales, insuficientes para capitalizar el desarrollo holístico del ser humano. En diferentes lugares, con disímiles culturas y situaciones sociales, las realidades poco halagadoras son cada vez más visibles. Ignorarlas, no favorece su solución, sino que prolongan y perpetúan la necesidad de una salida viable (Anderson, 2010).

En este sentido, es estudio busca el mejoramiento de la educación, con criterios de eficiencia académica, en armonía a los postulados nacionales (CEAACES, 2013), mediada por indicadores de calidad y calidez, hace que las políticas públicas y particulares estén orientadas a 
reformular directrices (Astudillo \& María, 2012), y plantean la posibilidad de asumir retos en los que se capaciten a los docentes, se evalúen a los estudiantes, a los padres de familia y la sociedad, encontrando alternativas que permitan la materialización del mejoramiento de la calidad de vida, en armonía con las políticas públicas del Plan Nacional para el Buen Vivir, 2013 - 2017, tal como se señala en el acápite de una nueva métrica, del acceso universal a bienes superiores, como parte de los objetivos generales (Secretaría Nacional de Planificación y Desarrollo - Senplades, 2013).

\section{Describe relevants scholarship}

Como se señaló, en los evangelios se reconoce que Jesús fue un predicador de éxito y un sanador célebre. Sin embargo, también se dice que fue un maestro por excelencia. Una variedad de episodios de enseñanza, experiencias de aprendizaje diseñadas para sus doce discípulos, como también para multitudes o para un solo individuo, dan cuenta del carácter y naturaleza de su obra. Su "Sermón del Monte" (Mateo 5.1 - 7:29) ilustra una sesión de clase al aire libre, en el cual participan sus discípulos y la multitud.

Este marco de aprendizaje difiere del actual. Desde tiempos del reduccionismo escolástico, cuando la educación se enclaustró al aula, al formato educativo nacido en determinado momento histórico, la práctica ha sido de continuo. Las prioridades educativas se han dado en el marco de la búsqueda del desarrollo del modo de producción capitalista y de la conformación de los estados nacionales (Krichesky, y otros, 2013). Ante este panorama, la pedagogía de Jesucristo es una alternativa que busca fomentar el desarrollo holístico del ser humano, proveyéndole de insumos que le permitan hacer frente a los diseños académicos que cada vez privan de la libertad y acondicionan el intelecto de los estudiantes (Chomsky, 2013), preocupación compartida por la Cumbre de la Innovación Mundial para la Educación (WISE), celebrada el 29 de noviembre del 2013.

En el caso del Ecuador, las posibilidades de mejoramiento de las prácticas pedagógicas, son altas. Existe un alto desconocimiento de estrategias educativas efectivas para una enseñanza sustancial, tanto de docentes fiscales de la sierra (Días, 2013), como de educadores de instituciones particulares de la costa ecuatoriana (Alvarado, 2013). Las carencias pedagógicas son sostenidas, ameritando la búsqueda de soluciones pertinentes, que generen un aprendizaje más eficiente, participativo y comprometido (Tobar, 2013) con la educación integral.

Los elementos pedagógicos del discurso de Jesucristo están matizados por enfoques disímiles: el discurso expositivo, el trabajo independiente, el trabajo en conjunto o en grupo, la atención individualizada y de representación vivenciada. Elementos que favorecen la posibilidad de articulación de enfoques metodológicos, contextualizados con las situaciones de aprendizaje y de acuerdo con la realidad actual.

Como parte de una respuesta a estos antecedentes, se busca considerar la significatividad de los elementos pedagógicos del discurso de Jesucristo, los que emergen desde los orígenes de la especie humana, continuando a través de la revelación profética, hasta la actualidad, a fin de reforzar la restauración y desarrollo holístico del ser humano. Elementos recurrentes en la 
enseñanza de Jesucristo, quien involucró a sus oyentes y el aprendizaje, de manera activa. Elementos relativos al ser, el saber, el hacer y el sostener.

\section{Elemento Ser}

Este término general, intenta incluir el ámbito de lo real en el sentido ontológico general, esto es en la realidad del sujeto por excelencia. En la búsqueda del desarrollo del ser, se replantean alternativas de fondo. Se advierte un giro pedagógico para la afirmación de elementos inherentes a la naturaleza humana (UNESCO, 2012), como solución a la problemática actual del quehacer educativo, y que son típicos tópicos de la revelación bíblica.

Por otro lado, la desatención en el desarrollo del ser - alumno, por parte de los educandos, crea desafectos. En un estudio de las experiencias educativas, percepciones e impacto, desarrollado en varias comunidades indígenas del Ecuador (Quishpe, 2007), se encontró que la identidad e individualidad de los docentes cada vez se deteriora con el tiempo. Se afirma que los valores y prácticas culturales son sostenidos de manera débil, ante el ímpetu de los medios y prácticas foráneas, las que subterráneamente se van insertando en el día a día de la mancomunidad educativa, y que terminan afectando a la sociedad en general.

Lo valoración del ser, mediado por lo afectivo, es un imperativo en el proceso de enseñanza. En una investigación sobre la educación rural en Nuevo León, México (Jaimes, 2011), señala que la búsqueda del desarrollo socio-afectivo de los estudiantes favorece su aprendizaje. Que esto beneficia la adquisición de principios y valores, lo que contribuye a su desarrollo personal y relacional. Por lo que el educador debe desarrollar destrezas que lo capaciten con calidad y excelencia profesional a fin de considerar la atención individualizada, que aúpen el desarrollo holístico de sus educandos.

En este sentido, la importancia del progreso del ser, se ve reflejada en las interacciones interpersonales. El desarrollo del ser tiene relación directa con el aprendizaje (Quishpe, 2007). Es una problemática compartida entre los actores del proceso enseñanza - aprendizaje. Alumnos y maestros de las instituciones educativas actuales replican similares problemas y desafectos recurrentes en las instituciones públicas y privadas. La sociedad percibe que la educación no está favoreciendo el desarrollo del ser de sus educandos, sino que cada día, los desafectos entre pares se fortalecen, evidenciando la necesidad de una convivencia pacífica, considerada como causa y consecuencia para una educación de calidad (Secretaría Nacional de Planificación y Desarrollo Senplades, 2013). El privilegiar el conocimiento de valores y estándares fundamentados en las enseñanzas del mayor maestro de la historia humana: Jesús (Anderson, 2010), fortalecerá las capacidades y potencialidades de la ciudadanía, en armonía a los objetivos nacionales para el buen vivir (Secretaría Nacional de Planificación y Desarrollo - Senplades, 2013).

La valoración de este elemento es posible ilustrarlo en el encuentro de Jesucristo con un experto de la ley, quien le preguntó: “¿Y quién es mi prójimo?” Jesús contó la historia del buen samaritano (Lucas 10.25-37), y entonces reformuló la pregunta para enfocar el aspecto del ser: “¿Cuál de estos tres piensas que demostró ser el prójimo?” Jesús también habló de la importancia de ejemplificar ciertas virtudes en la vida. "Sean compasivos," les animó, "así como su Padre 
celestial es compasivo." "Sean astutos como serpientes y sencillos como palomas." O simplemente, "Estad preparados".

La valoración del ser, por parte de Jesucristo, no tiene límites. Mientras enseñaba al pueblo, los escribas y fariseos le trajeron una mujer sorprendida en adulterio; y poniéndola en medio le dijeron: "Maestro, esta mujer ha sido sorprendida en el mismo acto del adulterio... En la ley Moisés nos mandó a apedrear a tales mujeres. Tú, pues, ¿Qué dices?”. Ante su insistencia el maestro les dice que el que estuviere libre de pecado que sea el primero en arrojar la piedra contra ella. Sus detractores, acusados por sus conciencias salieron desde los más viejos hasta los postreros. Luego el maestro no viendo a nadie sino a la mujer le dice: "Ni yo te condeno; vete" (Juan 8.1-11).

El ser humano, aún con sus fracasos es objeto de suprema consideración por parte del Maestro. La valoración del docente por sus estudiantes, permite la identificación con los intereses más nobles. Mejorando el clima de aprendizaje y la estima personal.

\section{Elemento Saber}

Para Jesucristo, el saber era de importancia. En ocasión de la visita de los Saduceos, éstos le presentaron otra situación problemática complicada, relativa a una mujer casada en forma consecutiva con siete hermanos, a la que Jesús les contestó, "Ustedes andan equivocados porque desconocen las Escrituras y el poder de Dios" Por medio de su enseñanza, Jesús enfatizó la importancia de conocer la verdad y de desarrollar un conocimiento experimentado de la realidad de las cosas.

Mediante el elemento saber, se hace referencia a un factor de aprehensión del conocimiento, visibilizado por interrogaciones recurrentes en el discurso de Jesucristo. Recurso de valoración histórica en el proceso de enseñanza y que en la actualidad tiene lugar en la multiplicidad de metodologías de aprendizaje, especialmente cuando del eclecticismo pedagógico se trata (Knight, 2002).

La forma de visibilizar el saber, con frecuencia era materializada por preguntas: "Qué piensan”, "Ellos pensaban dentro de sí", "Por qué pensáis dentro de vosotros" “Quién dicen los hombres que es el Hijo del Hombre?”, “QQuién dices que soy yo?” (Mateo 16.7, 13, 15). De esta forma, Jesucristo buscaba conocer el parecer de sus seguidores, sus opiniones, sus perplejidades. El saber, no puede existir de forma aislada del ser. Al final de su ministerio, después de lavar los pies de sus discípulos, Jesús les preguntó “¿Entienden lo que he hecho?”.

El conocimiento debido, fortalece la labor pedagógica por parte del docente. Por tres ocasiones Jesucristo inquirió de Pedro: “Simón, hijo de Jonás, ¿me amas más que éstos?” la respuesta siempre fue asertiva, por lo que el Maestro comisionó a Pedro, la labor a cuidar de los nuevos discípulos (Juan 21.15-17) evidenciando que quien prioriza su afecto y consideración por Jesucristo, está en mejores condiciones para enseñar.

En este caso, el término apacentar es un verbo activo que aparece nueve veces en el Nuevo Testamento; algunas versiones lo traducen como alimentar, guardar. Estas expresiones 
retratan el deber de un maestro en promover el bienestar espiritual de los miembros de la clase en todos los sentidos (Strong, 1996).

\section{Elemento Hacer}

Jesucristo resaltó el concepto de que el conocimiento debe materializarse en la práctica. Lo que el maestro es, se hace evidente en lo que hace, y esto se espera del estudiante. “Entienden esto? Dichosos serán si lo ponen en práctica (Juan 13.17)” El Maestro, enseñó que las acciones realizadas en la vida influyen sobre el destino. "No todo el que me dice: Señor, Señor, entrará en el reino de los cielos, sino sólo el que hace la voluntad de mi Padre que está en el cielo."

El análisis documental de la UNESCO (Blanco, 2007) en su informe sobre la situación educativa de América Latina y el Caribe y que reunió a sus ministros de educación para buscar alternativas de solución a esta problemática, señala cuatro pilares comunes para una educación relevante: aprender a ser; a conocer, a hacer y a vivir juntos, como factores fundamentales para una educación de calidad.

La importancia del hacer como valoración del aprendizaje, no es discutible. Desde las políticas y estrategias regionales de la Oficina Regional de Educación de la UNESCO (2009), se señala que la verdadera educación es más que la adquisición de conocimientos, incluye la puesta en práctica de dichos conocimientos, con el fin de salvaguardar y buscar el desarrollo sostenible del medio y las personas que en él habitan.

Asimismo, desde la perspectiva gubernamental ecuatoriana, (Ministerio de Educación del Ecuador, 2012) se señala que los estándares de calidad educativa se alcanzan si los estudiantes saben y hacen. Es decir, los conceptos adquiridos no son etéreos, sino que deben verse replicados en la práctica. Esto es señalado como un deber ineludible e inexcusable, enmarcado aún en la constitución política del país.

\section{Elemento Sostener.}

El elemento sostener denota la capacidad del estudiante para argumentar los aprendizajes. La interiorización y comprensión del conocimiento son fundamentales en este proceso. La capacidad de reflexionar y sostener los nuevos conocimientos, son las principales metas cualitativas y paradigmáticas para los docentes y estudiantes Briceño (2002), según lo tipifica la Ley Orgánica de Educación Superior del Ecuador, en su artículo 145, del capítulo 1, que favorece el principio de autodeterminación para la producción del pensamiento y conocimiento (Asamblea Nacional, 2010).

En este marco del apuntalamiento del saber, el Plan Nacional del Buen Vivir (Secretaría Nacional de Planificación y Desarrollo - Senplades, 2013), afirma que deben existir condiciones adecuadas de convivencia pacífica para maestros y autoridades, que brinden seguridad y que permitan el diálogo apropiado entre las partes intervinientes, con parámetros de respeto y de solidaridad. 
Finalmente, se podría concluir que, con tantos lugares para instruir, y con un periodo tan breve de ministerio disponible, Jesucristo enviaría a sus alumnos para que de manera individual aplicaron lo aprendido. Sin embargo, al comisionar a los doce discípulos los envió de dos en dos. De la misma manera envió a otros setenta. Cuando sus estudiantes regresaron, Jesús realizó una sesión de retroalimentación, en la que ellos "le contaron todo lo que habían hecho y lo que habían enseñado" (Marcos 6.30).

\section{State Hypotheses and Their Correspondence to Research Design}

La hipótesis planteada señaló que los elementos pedagógicos del discurso de Jesucristo, son significativos por parte de los nuevos estudiantes de la Universidad Internacional del Ecuador en el 2016. Su validación se dio por la significatividad de los factores intervinientes con la variable compuesta "Pedagogía de Jesús"

\section{Métodos}

En cuanto al diseño del estudio, este es descriptivo, cuantitativo, de campo, transversal y correlacional. Es descriptivo, porque detalló lo acontecido con los datos recolectados, para llegar a un entendimiento de los elementos pedagógicos del discurso de Jesucristo. Es cuantitativo, ya que por medio de un cuestionario se recopiló la información pertinente. Es de campo, porque se contó con la participación de los estudiantes que aplicaron para su ingreso a la Universidad Internacional del Ecuador, sede Guayaquil. Es transversal, porque el levantamiento de la información tuvo lugar una vez. Es correlacional, ya que la investigación relacionó factores pedagógicos con el discurso de Jesucristo, para acreditar el supuesto de estudio.

El universo de participantes del estudio fue de 42 estudiantes, quienes tomaron el curso de nivelación para el ingreso a la universidad en el primer semestre del 2016, con lo que se aseguró la validez interna y externa en el recojo de la data. Del total de estudiantes, 12 corresponden al género masculino y 30 al femenino. Sus edades estuvieron comprendidas entre los 17 y 27 años, cuya moda corresponde a los 18 años de edad.

El instrumento para la recopilación de la data, fue un cuestionario denominado "Elementos pedagógicos del discurso de Jesucristo" el mismo que constó de 16 indicadores recurrentes, con lo que se buscó su validación. El análisis de fiabilidad tuvo un coeficiente de 0,8576 expresado por el valor del alfa de Cronbach, con lo que se aseguró su confiabilidad.

\section{Participant (Subject) Characteristics}

La participación de los estudiantes fue voluntaria. Se contó con la población, por lo que no fue necesario tomar una muestra.

\section{Resultados}

El estudio buscó señalar la significatividad de los elementos pedagógicos del discurso de Jesucristo, por parte de los nuevos estudiantes de la Universidad Internacional del Ecuador, sede 
Guayaquil, en el 2016. Se encontró que los elementos pedagógicos del discurso de Jesucristo: ser, saber, hacer y sostener, si son significativos en el proceso de aprendizaje, de los estudiantes de la UIDE - Guayaquil, en el 2016.

Al medir el grado de relación, entre las variables predictoras y la variable dependiente "Elementos Pedagógicos del Discurso de Jesucristo", se encontró que existe correlación bivariada positiva significativa ( $\operatorname{ser}=, 732$; saber $=, 702$; hacer $=, 848$ y sostener $=, 692$ ) donde el elemento pedagógico hacer, registró mayor significatividad, seguido del factor ser. Esto en base al coeficiente de correlación de Pearson.

Los resultados muestran que, si son significativos los elementos pedagógicos del discurso de Jesucristo, para los nuevos estudiantes de la UIDE, lo que favorece su consideración para el proceso enseñanza - aprendizaje.Estos resultados permiten ver las potencialidades con que cuentan los estudiantes, en cuanto a la potenciación y materialización de los conocimientos que se imparten en las aulas. De igual manera, se ve la valoración por parte de los educandos, al compromiso más humano con que los educadores deben impartir sus conocimientos, en procura del desarrollo integral y holístico, como parte de las políticas institucionales.

Estos elementos pedagógicos del discurso de Jesucristo no son nuevos. Desde la narrativa del Antiguo hasta el Nuevo Testamentos, son recurrentes. Avalando y fundamentando lo visibilizado por la revelación profética y los resultados del presente estudio. Recursos que buscan la realización personal, colectiva, con el medio y con el Creador, en un marco de armonía y respeto, al tiempo que visibilizan el ideal divino de la redención. Así, una educación centrada en principios universales, no sólo apuntala la autoridad metodológica de los educadores, sino que también permite que, de manera mancomunada, los educandos alcancen un mejor desarrollo integral.

\section{Discusión}

La aplicación de elementos pedagógicos del discurso de Jesucristo, tenuemente mantenidos en el tiempo, no es tarea fácil. Se precisan medidas contracíclicas; migración de paradigmas, transferencia de procesos, construcción de capacidades pedagógicas por parte de los docentes, junto con el ejercicio de la voluntad política y del liderazgo educativo. La toma de conciencia individual, facilitará su materialización por parte los diversos actores del proceso enseñanza - aprendizaje.

La aplicación de los recursos pedagógicos de Jesucristo, no es un asunto prescriptivo. Sin embargo, la valoración de las nuevas narrativas que privilegian al ser humano, en un contexto participativo, como parte de los indicadores de la calidad educativa, son asuntos a tomarse en cuenta. Por su naturaleza, la aplicación de estos factores, será de gran valía tanto para estudiantes, como para docentes, favoreciendo el clima para un aprendizaje significativo y redentor, en armonía a la revelación neo testamentaria.

\section{Conclusión}

El análisis de correlación bivariada de Pearson, permite aceptar el supuesto de que el conjunto de factores de la pedagogía de Jesús: ser, saber, hacer y sostener, si son significativos, 
por parte de los estudiantes que ingresan a la Universidad Internacional del Ecuador en el primer semestre académico del 2016. Estos resultados concuerdan y se ajustan a la narrativa bíblica, a los estudios locales, nacionales y foráneos, en armonía con los postulados del Plan Nacional del Buen Vivir, en lo referente a la matriz educativa.

El factor "hacer" de los elementos pedagógicos del discurso de Jesucristo es el que registró una mayor significatividad, lo que permite establecer que los estudiantes aprenden mejor cuando tienen la posibilidad de materializar los conocimientos adquiridos, siendo este uno de requisitos indispensables en el aseguramiento de la calidad en todo proceso de formación, tal como se señala en el Plan Nacional del Buen Vivir (Secretaría Nacional de Planificación y Desarrollo - Senplades, 2013).

El factor "ser", sigue en significatividad, lo que revela que la capacidad de la valoración humanística e integral, y no sólo cognitiva por parte de los docentes a los estudiantes, es un imperativo para tomar en cuenta al momento de educar.La verdadera educación no sólo debe limitarse a la transmisión asertiva de contenidos, sino también al uso de metodologías apropiadas. En la valoración de las individualidades existe una alta recompensa: "brillar como la luz de las estrellas a perpetua eternidad" (Dan 12.3)

El establecimiento de una formación integral que permita alcanzar la sociedad del conocimiento, según el Plan Nacional del Buen Vivir (Secretaría Nacional de Planificación y Desarrollo - Senplades, 2013), que garantice a todos los derechos a la educación, bajo condiciones de calidad y equidad, y que promueva la investigación responsable con la sociedad y la naturaleza, encuentra eco en el discurso pedagógico de Jesucristo.

Como docentes, es pertinente considerar la vida y enseñanzas de Jesucristo. La familiaridad con sus métodos, su aproximación al corazón humano, su pedagogía, su compasión por las personas, siempre serán oportunos. Mientras más se contemple sus enseñanzas, más se percibirá su influencia. Esta realidad convoca a la búsqueda y replanteamiento de una matriz pedagógica que considere los elementos pedagógicos del discurso de Jesucristo, tendientes a apuntalar una educación de calidad para el presente y el futuro. Aunque mudar la radicalidad coyuntural pareciera una tarea utópica, al menos se propicia el debate para pensar, crear y asumir la responsabilidad que la temática en cuestión demanda. En muchos casos se precisan medidas contra cíclicas, divergentes con los enfoques pre - establecidos por la cultura educativa popular. Sin embargo, serán necesarias considerarlas, si se quiere posicionar una educación de calidad y redentora.

\section{Bibliografía}

Alvarado, B. (12 de Julio de 2013). Realidad de la práctica pedagógica y curricular en la educación ecuatoriana en la Unidad Educativa Liceo Cristiano De Guayaquil durante el año 2011 - 2012. Obtenido de utpl: http://cepra.utpl.edu.ec/bitstream/123456789/2902/1/

Anderson, S. (2010). Cómo matar la Educación Adventista y cómo darle una oportunidad. México: Asociación Publicadora Interamericana. 
Asamblea Nacional. (2010). Ley Orgánica de Educación Superior. Registro Oficial, Asamblea Nacional, Quito. Recuperado el noviembre de 2013

Astudillo, B., \& María, T. (27 de noviembre de 2013). Indicadores de calidad educativa en centros escolares del Distrito Metropolitano de Quito y propuesta de un modelo de calidad pertinente para el Ecuador. Obtenido de www.flacsoandes.org: http://hdl.handle.net/10469/5416

Barroso, H. (2000). Las Escuelas Normales de Sevilla durante el Siglo XX (1900 - 1970): tradición y renovación en la formación del magisterio primario. Sevilla: Universidad de Sevilla.

Brantley, P. (2000). La Administración: ¿Es el nexo que falta para la integración de la Fe y la Enseñanza? Revista de Educación Adventista, 15-19.

Briceño, N. (2002). Formación de Asesores de Pastoral Juvenil: Construcción Teórica Colectiva. Caracas: Universidad Andrés Bello.

CEAACES. (2013). Informe General sobre la Evaluación, Acreditación y Categorización de las Universidades y Escuelas Politécnicas. Dirección de Acreditación de Universidades y Escuelas Politécnicas, Quito. Recuperado el 27 de noviembre de 2013

Chavarrías, M. (7 de diciembre de 2006). Erosky Consumer. Recuperado el 28 de Julio de 2013, de http://www.consumer.es/web/es/alimentacion/tendencias/2006/12/07/25978.php

Chomsky, N. (2 de diciembre de 2013). Redacción Matrizur.org. Obtenido de Noam Chomsky: "Las universidades modernas están diseñadas para privar al estudiante de su libertad": http://www.matrizur.org/index.php?option=com_content\&view=article\&id=29173:noamchomsky-qlas-universidades-modernas-estan-disenadas-para-privar-al-estudiante-de-sulibertadq-\&catid=46: conocimiento-y-tecnologia\&Itemid=69

Departamento de Educación de la División Sudamericana de la Iglesia Adventista del Séptimo Día. (2009). Pedagogía Adventista. Buenos Aires: ACES.

Días, J. C. (12 de junio de 2013). Realidad de la Práctica Pedagógica y Curricular en la Educación Ecuatoriana en los estudiantes de Educación Básica y Bachillerato del Colegio Nacional "Primero de Abril" de la ciudad de Latacunga, en el Año Lectivo 2011-2012. Obtenido de cepra.utpl.edu.ec:

http://cepra.utpl.edu.ec/bitstream/123456789/2917/1/Tesis\%20de\%20Diaz\%20Alvarez\%20J uan\%20Carlos.pdf

Hamel, G., \& Breen, B. (2008). El Futuro de la Administración. Bogotá: Norma.

Jaimes, D. (2001). La Escuela Rural en Montemorelos, Nuevo León, México: Un Estudio de Casos. Memorias 2000 del Centro de Investigación Educativa, 36-61.

Knight, G. (2002). Filosofía y Educación. Una introducción a la perspectiva cristiana. Bogotá: Asociación Publicadora Interamericana. 
Krichesky, M., Borzese, D., Camors, J., Costas, P., Monteiro Machado, E., Nájera Martínez, E. M., . . - Wanger, L. (1 de Julio de 2013). UNIPE: Universidad Pedagógica. Obtenido de http://unipe.edu.ar/wp-content/uploads/2011/11/Cuaderno

Martínez, A. M., Navarro Asencio, E., Vale Vasconcelos, P., \& Redondo Duarte, S. (2009). Orientación educativa: fundamentos teóricos, modelos institucionales y nuevas perspectivas. Madrid: Secretaría General Técnica. Centro de Publicaciones. Ministerio de Educación.

Ministerio de Educación del Ecuador. (2011). Estándares de Calidad Educativa. Quito: Ministerio de Educación del Ecuador.

Oficina Regional de Educación para América Latina y el Caribe. (2008). Situación educativa de América Latina y el Caribe: Garantizando la educación de Calidad para todos. Santiago de Chile: Salesianos Impresores S.A.

Pagán, C. (Julio de 2013). La Pedagogía de Jesús. Obtenido de Apuntes Teológicos: http://www.angelfire.com/pe/jorgebravo/pedagogia.htm

Quishpe, C. (2007). Estudio de las Experiencias Educativas que se desarrollan en las Comunidades Indígenas de Cotopaxi, Percepciones y su Impacto para una propuesta común. Quito: Universidad Andina Simón Bolívar.

Rasi, H., Brantley, P., Akers, G., Fowler, J., Knight, G., Mathews, J., \& Thayer, J. (2002). Declaración sobre la Filosofía Advenitsta de la Educación. Revista de Educación Adventista, 15-18.

Salgado, C. (2009). Políticas, estrategias y planes regionales, subregionales y nacionales en eduación para el desarrollo sostenible y la educación. Santiago: UNESCO.

Secretaría Nacional de Planificación y Desarrollo - Senplades. (2013). Plan Nacional Para El Buen Vivir 2013-2017 (Primera edición ed.). (F. Falconí, Ed.) Guayaquil: El Telégrafo. doi: ISBN978-9942-07-448-5

Strong, J. (1996). Woodside Bible Fellowship. Ontario.

Tobar, B. (21 de Julio de 2013). La pedagogía de Jesús. Una propuesta sentipensante para construir sujetos participativos. Obtenido de http://revista.ecaminos.org/article/la-pedagogia-de-jesusuna-propuesta-sentipensante-/

UNESCO. (octubre de 2012). Innovaciones Educativas para América Latina y el Caribe. Boletín de octubre. Santiago: UNESCO.

Vélez van Meerbeke, A., \& Roa González, R. (junio de 2005). Educación Médica. Recuperado el 28 de Julio de 2013, de http://scielo.isciii.es/scielo.php?pid=s1575$18132005000200005 \&$ script=sci_arttext

White, E. (2015). La educación (Cuarta ed.). Buenos Aires: Aces. 